УДК 336.71

\author{
Посная Елена Анатольевна, Колесников Александр Михайлович, \\ Антохина Юлия Анатольевна
}

\title{
ВЛИЯНИЕ ЭФФЕКТИВНОГО МЕНЕДЖМЕНТА БАНКОВСКОГО КАПИТАЛА НА РАЗВИТИЕ ИНФРАСТРУКТУРНОЙ ИПОТЕКИ
}

На сегодняиний день достаточно актуальныи направлением экономического развития является государственно-частное партнерство по развитию инфраструктуры. Банковские учрежсдения в этом вопросе занимают лидируюцую позицию, поскольку именно они являются посредниками в реализации инфраструктурных програми, осуцествляя кредитование проектов, ориентируясь на ключевую ставку Центрального банка Российской Федерации. Традиционно сложсилось, что в инфраструктурных проектах значительную роль - порядка $60 \%$ финансирования - играют банковские учреждения. Поэтому ключевыми моментами в исследовании является определение значимости инфраструктурной ипотеки для субъектов хозяйствования и влияние эффективного менеджмента капитала банка на инфраструктурную ипотеку.

В правительстве РФ присутствует идея фонда развития инфраструктуры, который должен стать иентральным элементом механизиа инфраструктурной ипотеки. Фонд позволит запустить механизм двойного рычага - функция софинансирования проекта будет сочетаться с привлечением средств через выпуск облигаций фонда по госгарантии. Таким образол, в исследовании расслотрены вопросы теоретической и практической значимости инфраструктурной ипотеки и управления банковским капиталом для успешной реализации программы инфраструктурной ипотеки в РФ.

Ключевые слова: инфраструктура, инфраструктурная ипотека, банк, капитал банка, рычаг, механизм, кредит, ключевая ставка.

\section{Elena Posnaya, Aleksandr Kolesnikov, Yulia Antokhina INFLUENCE OF BANK CAPITAL EFFICIENT MANAGEMENT ON THE DEVELOPMENT OF INFRASTRUCTURAL MORTGAGES}

At present, a fairly relevant area of economic development is a state-private partnership for infrastructure development. Banking institutions in this matter occupy a leading position, since they are mediators in the implementation of infrastructure programs, fulfilling lending projects, focusing on the key rate of the Central Bank of the Russian Federation. Traditionally, in infrastructure projects a significant role - about $60 \%$ of funding is played by banking institutions. Therefore, the key points in the study are to determine the significance of the infrastructure mortgage for business entities and the impact of effective bank capital management on the infrastructure mortgage.

The government of the Russian Federation has the idea of an infrastructure development fund, which should become a central element of the infrastructure mortgage mechanism. In the event of a launch, the fund will allow launching a double lever mechanism - the project's co-financing function will be combined with raising funds through the issuance of fund bonds for state guarantees. Thus, the study examined the theoretical and practical significance of the infrastructure mortgage and bank capital management for the successful implementation of the infrastructure mortgage program in the Russian Federation.

Key words: Infrastructure, infrastructure mortgage, bank, bank capital, lever, mechanism, loan, key rate.

Bведение / Introduction. В настоящее время в Российской Федерации появился новый инструмент для развития экономики и роста ее темпов - инфраструктурная ипотека. Это рассматривается как государственно-частное партнерство, когда частный инвестор сможет кредитовать государство по привлекательным и приемлемым для него ставкам в части строительства дорог, газопроводов. Эксперты согласны, что данные мероприятия помогут экономике и развитию инфраструктуры страны, но высокая доходность - это открытый вопрос. Этот инструмент первым в 
публичном правовом пространстве начал открыто обсуждать бизнесмен-омбудсмен Борис Титов, который также представил «Стратегию роста», связанную с повышением темпов наращивания ВВП. Ипотека является видом кредита под залог, при этом право распоряжения предметом залога остается у должника. Если ипотека является инфраструктурной, то частное лицо сможет прокредитовать государственный проект, например, по строительству мостов, дорог, зданий, сооружений, при этом гарантированно получать доход. Возврат капиталовложений частных инвесторов в проекты предлагается производить за счет регулярных платежей, которые будут поступать от основных выгодоприобретателей объектов инфраструктуры. То есть инфраструктурная ипотека позволит реализовывать крупные проекты с привлечением платежей пользователей и частных инвесторов. Таким образом, при инфраструктурной ипотеке объект по факту приобретается в кредит, полученный от частных инвесторов, а пользователь объекта постепенно погашает этот кредит.

Инфраструктурная ипотека позволит обеспечить опережающие темпы роста экономики. По мере получения доходности осуществляется возврат средств от пользователей инфраструктуры. При этом государство также является участником. Помимо условий гарантии таким инвесторам, государство в том числе за счет бюджетных средств может быть пользователем инфраструктуры и платить постепенными взносами инвестору ту часть вложений, осуществленных с учетом доходности, которая ранее была оговорена и документы по которой подписаны [1].

Результаты и обсуждение / Results and discussion. Инфраструктурная ипотека - новый финансовый инструмент наряду с проектным финансированием. Успех реализации инфраструктурной ипотеки напрямую зависит от доходности [2].

Минимум стоимости кредитования в Российской Федерации 7,5 \% (ключевая ставка Центрального банка), а инфраструктурная ипотека должна стоить 2-3 \%, выдаваться под гарантии холдинга или его активы, иметь реальный итог в виде осязаемых объектов: дорог, станций, развязок, линий связи, зданий, сооружений, оборудования и т. д. [3]. Все это позволит увеличить рост ВВП России [4].

Формирование, функционирование, эффективное управление банковским капиталом позволит более быстрыми темпами развиваться инфраструктурной ипотеке [5].

Понятие «капитал банка» является центральным в банковской деятельности. Это связано с ролью, которую выполняет капитал в деятельности банка. Стартовый капитал банка является обязательной предпосылкой для начала его деятельности, в дальнейшем за счет возрастания доверия к банковскому учреждению он дает возможность привлекать средства клиентов и набирать взаймы средства кредиторов [6]. На протяжении периода функционирования банка именно через капитал (его размер) Центральным банком Российской Федерации ведется регулирование его деятельности с целью снижения рисков и недопущения перенесения их на клиентов и кредиторов каждым отдельным банком и ради поддержки стабильности банковской системы в целом [7].

Капитал банка является сложным социально-экономическим объектом, поэтому его следует рассматривать в качестве системы.

Сложность и многогранность категории «капитал» существенно повлияли на трактовку понятия «банковский капитал», в которую (в зависимости от контекста) вкладывается разное содержание. В отечественной и зарубежной экономической литературе и практике для характеристики банковского капитала используются разные термины, в частности: «совокупность денежных капиталов», «банковские ресурсы», «собственные средства», «ресурсная база банка». Термин «ресурсная база банка» является наиболее пригодным с точки зрения разработки стратегических основ формирования банковских ресурсов по сравнению с термином «банковские ресурсы», который отображает средства, уже фактически находящиеся в распоряжении банков. То есть термин «ресурсная база банка» характеризует возможность привлечения банками с денежного рынка средств, которые уже принимают участие в банковском обороте или еще не принимают, создавая 
основы развития и расширение банковской деятельности. Поскольку вообще под ресурсами понимают возможности, средства, запасы чего-нибудь, которые можно использовать в случае потребности, под банковскими ресурсами понимается совокупность денежных средств и выраженных в денежной форме материальных, нематериальных и финансовых активов, которые находятся в распоряжении банков и могут быть использованы ими для осуществления банковских операций и предоставления услуг [8].

Опираясь на определение банковских ресурсов, критическое изучение взглядов на понятие «банковский капитал», предложено определение банковского капитала, которое характеризует его как часть банковских ресурсов, привлеченных банками в оборот и используемых ими с целью получения прибыли. Затем в любой момент ресурсы банка больше или равны его капиталу. Равенство означает, что все имеющиеся ресурсы используются продуктивно, т. е. для получения прибыли. Указанное дает возможность схематично изобразить взаимосвязь между терминами «ресурсная база банка», «банковские ресурсы», «банковский капитал» на рисунке ниже.

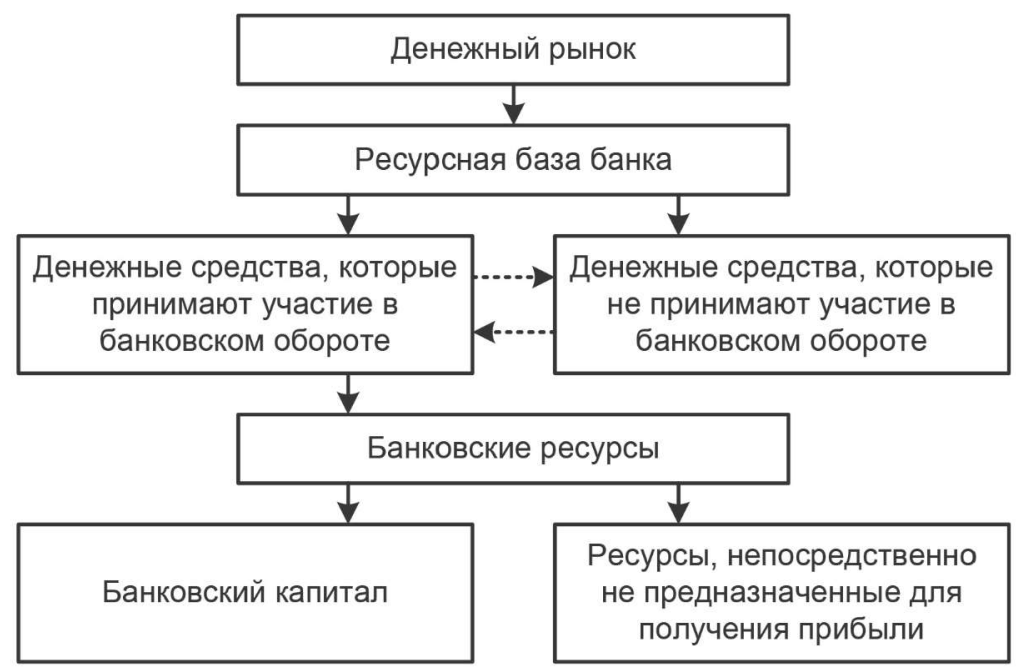

Рис. Взаимосвязь между терминами «ресурсная база», «банковские ресурсы», «банковский капитал»

Вопрос классификации банковского капитала является дискуссионным и недостаточно освещенным в экономической литературе. Используется один или несколько критериев, преимущественно выделяются собственный и привлеченный капитал. Такой подход существенным образом ограничивает возможности познания сущности, закономерностей формирования и функционирования банковского капитала.

Методы пополнения капитала как основа эффективного управления

\section{Метод внутренних источников пополнения капитала:}

1) определение величины капитала, которую банк может привлечь за счет нераспределенной прибыли;

2) оценка и выбор наиболее оптимального внешнего источника пополнения капитала на основании анализа рыночных условий, прав и интересов собственников, прогнозов относительно будущей прибыльности банка.

С целью пополнения капитала и получения значительных денежных средств банки прибегают к проведению таких финансовых операций, как продажа активов, в том числе зданий, сооружений, офисов, которые принадлежат банку, с долгосрочной арендой у новых владельцев. Такие операции становятся успешными в условиях, когда через инфляцию рыночная стоимость 
имущества значительно возрастает, а законодательством разрешена ускоренная амортизация недвижимости. Чаще в банках создаются резервы переоценивания основных средств для покрытия разницы между их рыночной и балансовой стоимостью. На сумму дооценки активов выпускаются акции, которые бесплатно размещаются между акционерами банка, увеличивая долю их собственности.

Такая операция капитализации резервов и дооценивания активов называется бонусной эмиссией. Бонусная эмиссия увеличивает размер капитала, не распыляя собственность и не повышая риск потери контроля над банком со стороны акционеров. Выбор способа привлечения капитала из внешних источников должен базироваться на результатах глубокого финансового анализа альтернативных вариантов и их потенциального влияния на размер прибыли в расчете на акцию.

Менеджменту банка необходимо принять во внимание относительную стоимость и риск, связанный с каждым источником, методы государственного регулирования и доступности, а также оценить долгосрочные перспективы и последствия. Для отечественных банков эмиссия акций - фактически единственный внешний источник пополнения капитала. Преимуществом этого способа является возможность быстро получить значительные суммы денежных средств, а также улучшить позиции банка по привлечению средств в будущем.

Но такой подход имеет ряд существенных недостатков, которые следует принимать во внимание:

1) высокая стоимость;

2) трудности, связанные с размещением акций на рынке;

3) значительное повышение риска снижения доходов на одну акцию;

4) ослабление контроля над банками со стороны акционеров, если они не смогут сами выкупить все акции новой эмиссии [9].

Усиливающееся внимание к увеличению капитала ведет к тщательности стратегического планирования. Планирование собственного капитала должно осуществляться на основе общего стратегического плана. Определяются темпы роста активных операций, источники их финансирования, прогнозируемый размер и состав активов по степени риска. Исходя из этого рассчитывается необходимая величина капитала, привлекаемая за счет внешних источников. Источниками собственного капитала для банка являются накопление прибыли, дивидендная политика, прирост стоимости имущества за счет переоценки собственных зданий и оборудования.

\section{- Метод внешних источников пополнения капитала.}

Внешние источники пополнения капитала банка независимы от конъюнктуры рынка, у них нет расходов на привлечение капитала извне, нет угрозы потери контроля над банком со стороны акционеров. Но они подлежат полному налогообложению, возникают проблемы уменьшения дивидендов, идет медленное наращивание капитала [10].

Банки, растущие быстрее, чем это позволяет норма внутреннего роста капитала, должны привлекать дополнительный капитал из внешних источников. Это продажа обыкновенных и привилегированных акций, эмиссия капитальных долговых обязательств, продажа активов и аренда основных фондов.

Банковские учреждения заинтересованы в привлечении внешнего капитала, поскольку это даст дополнительную возможность для наращивания экономического потенциала, увеличения объемов деятельности.

Выбор способа привлечения внешнего капитала должен производиться на основе финансового анализа имеющихся альтернатив и их потенциального влияния.

Заключение / Conclusion. Таким образом, при эффективном управлении банковским капиталом, которое выражается в формировании, привлечении, оценивании, функционировании, в перспективе можно расширить объемы инфраструктурной ипотеки, существенно нарастив инвестиции в транспорт, энергетику, социальную инфраструктуру. Реализация инфраструктурной 
ипотеки станет не только значимым источником новых инвестиций, но и эффективным механизмом развития и углубления финансового рынка. Подписано соглашение крупнейших банков Российской Федерации - Сбербанк, ВТБ, Газпромбанк - с Внешэкономбанком о том, что касается «фабрики проектного финансирования». То есть банки готовы принимать участие в реализации программы инфраструктурной ипотеки.

\section{ЛИТЕРАТУРА И ИНТЕРНЕТ-РЕСУРСЫ}

1. Райзберг Б. А., Лозовский Л. Ш., Стародубцева Е. Б. Современный экономический словарь. 5-е изд., перераб. и доп. М.: ИНФРА-М, 2007. 495 с.

2. Силуанов: ставка по ипотеке должна быть $8 \%$ к 2024 году / Банки.ру [Электронный ресурc]. URL: http://www.banki.ru/news/lenta/?id=10690776

3. Минфин России подвел итоги сбора заявок от банков на участие в программе субссидирования льготной ипотеки под $6 \%$ / Министерство финансов РФ [Электронный ресуpc] URL: https://www.minfin. $\mathrm{ru} / \mathrm{ru} / \mathrm{press}-\mathrm{center} /$ ?id_4= 35031 \&mode_4=default\&area_id=4\&page_id $=2119 \&$ popup $=Y$

4. Медведев заявил о необходимости более доступной ипотеки / Известия [Электронный ресурc] URL: https://iz.ru/775005/2018-08-06/medvedev-zaiavil-neobkhodimosti -bolee-dostupnoi-ipoteki

5. Медведев призвал добиться дальнейшего снижения ставок по ипотеке / Известия [Электронный ресурс] URL: https://iz.ru/775029/pavel-panov/medvedev-prizval-dobitsia-dalneishego-snizheniia-stavokpo-ipoteke

6. Торосян Н. Д. Ипотечное кредитование: факторы развития, риски, способы фондирования, особенности обратной ипотеки // Экономика и предпринимательство. 2018. № 8-4 (85). С. 1059-1065.

7. Олейникова И. П. Рынок ипотеки в России: современная динамика и перспективы роста // Вызовы и возможности финансового обеспечения стабильного экономического роста (ФИНАНСЫ-2017): материалы Всероссийской научно-практической конференции 13-16 сентября 2017 г.: сборник научных трудов. Севастополь: РИБЕСТ, 2017. С. 117-125.

8. Нурбобоева М. Р. Современное состояние и перспективы ипотеки в России: региональный аспект // Инновационное развитие современной науки: проблемы, закономерности, перспективы: сборник статей V Международной научно-практической конференции. Пенза: Наука и Просвещение, 2017. C. $92-94$.

9. Posnaya E. A. and etc. The Economic Capital Model in Bank's Capital Assessment / E. A. Posnaya, E. V. Dobrolezha, I. G. Vorobyova, G. P. Chubarova // Chapter 12 in Simon Grima, Eleftherios Thalassinos (ed.) Contemporary Issues in Business and Financial Management in Eastern Europe (Contemporary Studies in Economic and Financial Analysis, Volume 100). Emerald Publishing Limited, 2018. Pp. 111-119.

10. Posnaya E. A. and etc. Methodology and Results in Bank Capital Assessment / E. A. Posnaya, S. V. Tarasenko, I. G. Vorobyova, E. V. Dobrolezha // European Research Studio Journal, 2018. Vol. XXI, Special Issue 1. P. 518-534.

\section{REFERENCES AND INTERNET RESOURCES}

1. Raizberg, B., Lozovsky, L., Starodubtseva, E. Sovremennyj ehkonomicheskij slovar (Modern economic dictionary). 5th ed. M.: Infra-M, 2007. $495 \mathrm{~s}$.

2. Siluanov: stavka po ipoteke dolzhna byt' $8 \%$ k 2024 godu (Siluanov: the mortgage rate should be $8 \%$ by 2024). URL: http://www.banki.ru/ news/lenta/?id=10690776

3. Minfin Rossii podvel itogi sbora zay avok ot bankov na uchastie $\mathrm{v}$ programme subsidirovaniya l'gotnoj ipoteki pod $6 \%$ (The Ministry of Finance of Russia has summed up the collection of applications from banks for participation in the subsidized mortgage subsidy program at $6 \%$ ) / Ministerstvo finansov RF [EHlektronnyj resurs]. URL: https://www.minfin.ru/ru/press-center/?id_4=35031 \&mode_4=default\&area_id=4\&page_id $=2119 \&$ popup $=Y$

4. Medvedev zayavil o neobhodimosti bolee dostupnoj ipoteki (Medvedev said the need for more affordable mortgage) / Izvestiya [EHlektronnyj resurs]. URL: https://iz.ru/775005/2018-08-06/medvedev-zaiavilneobkhodimosti -bolee-dostupnoi-ipoteki 
5. Medvedev prizval dobit'sya dal'nejshego snizheniya stavok po ipoteke (Medvedev urged to achieve a further reduction in mortgage rates) / Izvestiya [EHlektronnyj resurs]. URL: https://iz.ru/775029/pavelpanov/medvedev-prizval-dobitsia-dalneishego-snizheniia-stavok-po-ipoteke

6. Torosyan N.D. Ipotechnoe kreditovanie: faktory razvitiya, riski, sposoby fondirovaniya, osobennosti obratnoj ipoteki (Mortgage lending: development factors, risks, ways of funding, feature of the reverse mortgage loan), Economy and Entrepreneurship. №8-4 (85). 2018. Pp. 1059-1065.

7. Oleynikova I. P. Rynok ipoteki v Rossii: sovremennaya dinamika i perspektivy rosta (The mortgage market in Russia: current dynamics and growth prospects) // Vyzovy i vozmozhnosti finansovogo obespecheniya stabil'nogo ehkonomicheskogo rosta (FINANSY-2017): materialy Vserossijskoj nauchno-prakticheskoj konferencii 13-16 sentyabrya 2017 g.: sbornik nauchnyh trudov. Sevastopol': RIBEST, 2017. S. 117-125.

8. Nurboboeva M. R. Sovremennoe sostoyanie i perspektivy ipoteki v Rossii: regionalnyj-aspekt (Modern status and prospects of mortgage in Russia: regional aspect) // Innovacionnoe razvitie sovremennoj nauki: problemy, zakonomernosti, perspektivy: sbornik statej V Mezhdunarodnoj nauchno-prakticheskoj konferencii. Penza: Nauka i Prosveshchenie, 2017. S. 92-94.

9. Posnaya E. A. and etc. The Economic Capital Model in Bank's Capital Assessment / E. A. Posnaya, E. V. Dobrolezha, I. G. Vorobyova, G. P. Chubarova // Chapter 12 in Simon Grima, Eleftherios Thalassinos (ed.) Contemporary Issues in Business and Financial Management in Eastern Europe (Contemporary Studies in Economic and Financial Analysis, Volume 100). Emerald Publishing Limited, 2018. Pp. 111-119.

10. Posnaya E. A. and etc. Methodology and Results in Bank Capital Assessment / E. A. Posnaya, S. V. Tarasenko, I. G. Vorobyova, E. V. Dobrolezha // European Research Studio Journal, 2018. - Vol. XXI, Special Issue 1. Pp. 518-534

\section{СВЕДЕНИЯ ОБ АВТОРАХ}

Посная Елена Анатольевна, кандидат экономических наук, кафедра «Финансы и кредит», Севастопольский государственный университет, г. Севастополь, Россия. E-mail: sntulena $a$ mail.ru

Колесников Александр Михайлович, доктор экономических наук, профессор, кафедра экономики высокотехнологичных производств, Санкт-Петербургский государственный университет аэрокосмического приборостроения, г. Санкт-Петербург, Россия. E-mail:

Антохина Юлия Анатольевна, доктор экономических наук, профессор, ректор, Санкт-Петербургский государственный университет аэрокосмического приборостроения, г. Санкт-Петербург, Россия. Еmail: antoxina.j@yandex.ru

\section{INFORMATION ABOUT AUTHORS}

Elena Posnaya, Candidate of Economic Sciences, Department «Finance and credit», Sevastopol state University, Sevastopol, Russia. E-mail: sntulena@mail.ru

Alexander Kolesnikov, Doctor of Economic Sciences, Professor, Department of Economics of high-tech industries, St. Petersburg state University of aerospace instrumentation, St. Petersburg, Russia. E-mail: $9843039 @$ mail.ru

Yulia Antokhina, Doctor of Economic Sciences, Professor, rector, St. Petersburg state University of aerospace instrumentation, St. Petersburg, Russia. Email: antoxina.j@yandex.ru 